\title{
Time-shared, perceptual-motor skills during 7 days of isolation '
}

SEWARD SMITH AND THOMAS I. MYERS NAVAL MEDICAL RESEARCH INSTITUTE, BETHESDA, MARYLAND

Forty Ss attempted to remain in dark, quiet sensory deprivation (SD) for seven days. Twenty Ss lived individually in a live-in-the-lab control condition (C) affording much recreational activity. Nineteen $S D s$ but only one $C$ requested early release. SDs out-performed $C s$ on a time-shared perceptualmotor task which involved tracking, turning off location-coded tones, and turning off a noise. These data are further evidence that performance enhancement sometimes occurs during SD.

Results of prior studies of sensory deprivation (SD) indicate evidence of enhancement as well as decrement in performances of persons undergoing multi-day isolation (Myers, Murphy, Smith, \& Goffard, 1966; Smith, Myers, \& Murphy, 1967; Zubek, Aftanas, Hasek, Sansom, Schludermann, Wilgosh, \& Winocur, 1962; Zubek, Pushkar, Sansom, \& Gowing, 1961). However, to date, no complex time-shared task performances have been evaluated during $\mathrm{SD}$. To meet this need a demanding time-shared, perceptual-motor-skills task was developed for use during project COMONOT (Comparative Monotony).

Method

Two groups of volunteer U.S. Navy enlisted men were involved in the data collection reported here. They had a mean age of 18.5 years and an $I Q$ average of 112 , as estimated by the GCT portion of the Navy Classification Battery. Forty Ss comprised the SD group, who attempted to remain alone for seven days in a totally dark, soundproof room, with very little to do. Another $20 \mathrm{Ss}$ served as a live-in-the-lab control group (C) that was provided many activities to occupy the seven-day period. Each C S also lived alone, but had ad lib access to lights, recreational materials, and intercom conversation with another $C S$ if mutually desired. Details of the instrumentation and procedure employed are avallable in other reports (Smith, Myers, \& Edmondo, 1967; Smith, Myers, \& Johnson, 1967; Smith, Myers, Johnson, Milstein, Walsh, Marlow, \& Kushner, 1967).

The time-shared, perceptual-motor-skills task s1multaneously involved tracking, keeping a white nolse turned off, and turning off location-coded tones. All three tasks required different controlling actions. S tracked the irregular pattern traced out by one row of 12 lights, using a control knob to attempt to produce the same serial pattern with a second row of lights. The noise and tone tasks were presented to $S$ through binaural earphones. Whenever a nolse appeared he pulled a lever switch to turn it off. Tones appeared in his left or right ear, or in both ears (thus appearing to be located in the center). He used three side-byside, push-button switches to turn off these location- coded tones. An unnatural control-display relationship was imposed to add difficulty. Hence, $S$ pressed the left switch to turn off a tone to his right ear, etc. In general, having to perform the three tasks simultaneously was difficult and confusing. Figure 1 shows the relationship among the tasks.

Forty 20 sec trials of the combined task were given, with $10 \mathrm{sec}$ rest periods between trials and a $1 \mathrm{~min}$ rest at the end of each 10-trial block. The test was given about $43 \mathrm{~h}$ prior to entry into isolation. It was given twice during isolation, at approximately the 53rd and 125th hour after beginning isolation. While testing was in progress the rooms were dark and C Ss' entertainment systems were shut off.

The following scores were recorded: time on target in tracking (when the corresponding lights of the two rows were on); time tones kept off; time noise kept off; switch-press errors; and a total-task score (defined as the total time that $S$ was on target in tracking and simultaneously had no tone or noise in his earphones). The time-shared, perceptual-motor-skllis task is fully detailed in another paper (Smith, 1966).

\section{Results}

Because the total-task score represented all subtasks, it was the principal measure used for analyses. Group mean total-task scores (including all 40 trials) for each test day, are shown in Fig. 2. Analysis of variance of these data, including only those Ss who took the test all three times, reveals improved performance over days $(p<.001)$. The significant interaction $(p<.05)$ indicates that, although the groups performed similarly prior to introduction of experimental treatments, the SD

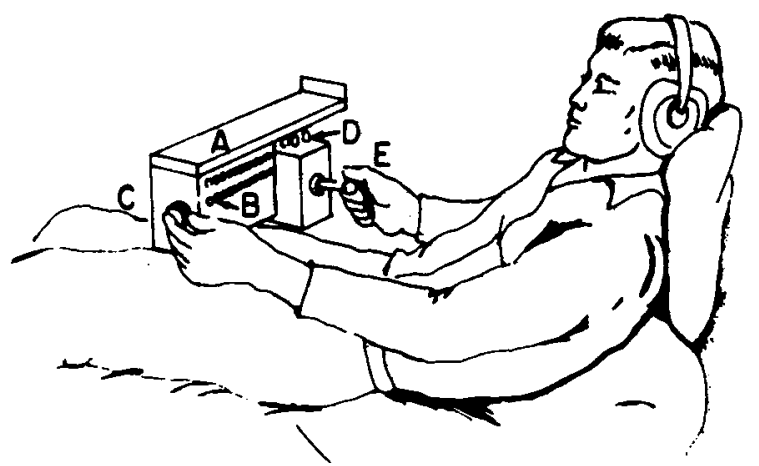

Fig. 1. Details of S's combined taks. $S$ has matched the illuminated tracking program light of the upper row of lights (A) with the correct light in the lower row (B) by means of the rotary switch knob (C). Tone and noise cues are presented through earphones. $S$ uses the three pushbutton switches (D) to tum off bcation-coded tones. He is shown turning off a noise cue by pulling the lever switch (E). 


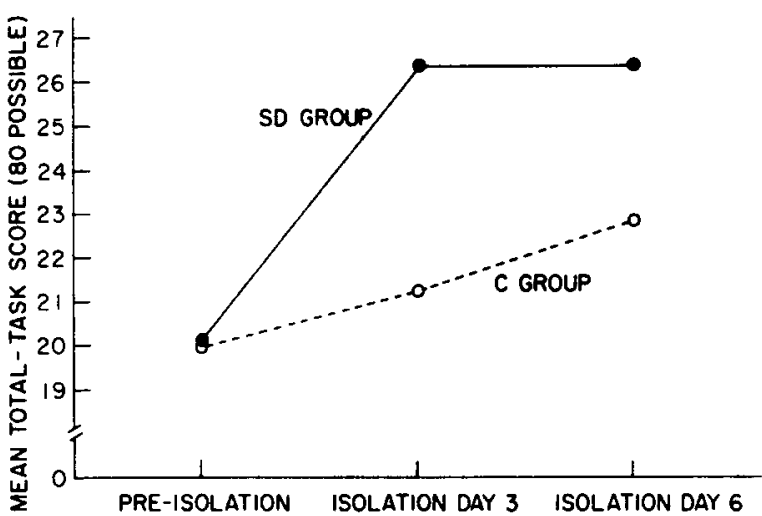

Fig. 2. Total-task scores for the SD group $(\mathrm{N}=20)$ and $\mathrm{C}$ group $(\mathrm{N}=17)$.

Ss exhibited a greater improvement during isolation than did Cs. Total-task scores of Ss requesting early release did not differ rellably from those of long staying Ss. Hence, early performance on the task did not relate to endurance. Comparisons of the SD and $\mathrm{C}$ groups by means of $t$ ratios, utilizing the full $\mathrm{Ns}$ who took the perceptual-motor test on any day, bear out the results of the above analysis of variance.

An examination of errors made (while attempting to turn off tones and noises) reveals a similar picture as shown in Fig. 3. Analysis of these data reveals only a significant interaction ( $p<.005)$. While SD Ss generally made more errors on the baseline test, they were less error prone during isolation than were C Ss.

\section{Discussion}

The results of this experiment reveal that Ss undergoing monotonous SD out-performed C Ss who were in a condition that afforded a virtual stimulus cafeteria when specific testing was not in progress. This is true in spite of the fact that the $\mathrm{SD}$ condition was apparently difficult and stressful for many Ss (e.g., 19 of $40 \mathrm{SD}$, but only 1 of $20 \mathrm{C} \mathrm{Ss}$ requested early release $(p<.001)$.

Questionnaire data gathered after Ss emerged from isolation failed to reveal differences between SD and C Ss with regard to how motivated they were to do well on the perceptual-motor task, or how difficult they found that task to be. In fact, the only questionnaire measure to approach significance was a more frequent noting by SD Ss that the task was tiring.

There is evidence that SD Ss are in a hypoaroused state throughout much of their confinement experience (Myers et al, 1966). Conversely, there is also evidence of at least temporary hyperarousal. In previous experiments involving a low-demand vigilance task, SD Ss demonstrated greater during-isolation vigilant alertness than did C Ss (Smith et al, 1967). The current

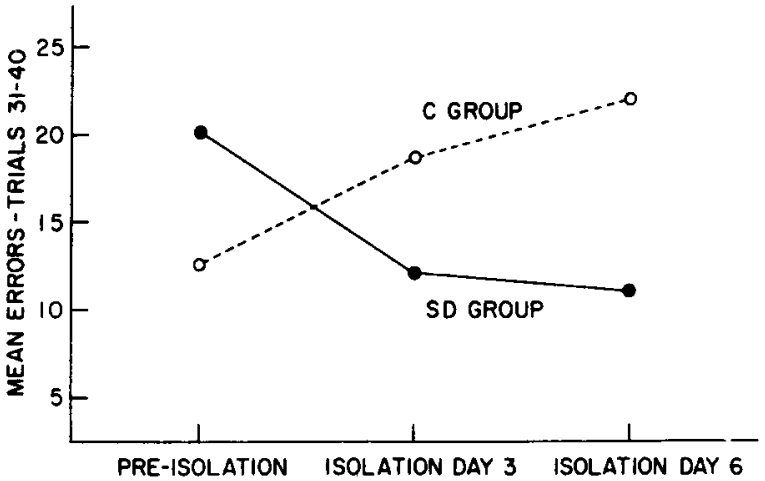

Fig. 3. Mean errors made by the SD group $(\mathrm{N}=21)$ and $\mathrm{C}$ group ( $\mathbf{N = 1 9 ) . ~}$

data lend further support to the assumption that the generally hypoaroused SD S is hyperarousable in the presence of certain stimulation sources. This may yield performance enhancement (as above) but could be disruptive in complicated mental manipulations, where over-attention to intruding stimuli might block proper utilization of other, more relevant information.

\section{References}

MYERS, T. I., MURPHY, D. B., SMITH, S., \& GOFFARD, S. J. Experimental studies of sensory deprivation and social isolation. Tech. Rep. 66-8, June, 1966. Alexandria, Va.: Human Resources Research Office.

SMITH, S. Development of a complex, time-shared, perceptual-motor skills task for use in studies of isolation and confinement. Res. Rep. No. 15, Aug., 1966. Bethesda, Md.: Naval Medical Research Institute.

SMITH, S., MYERS, T. I., \& EDMONDO, P. M. The NMRI deep isolation laboratory. Res. Rep. No. 27, May, 1967, Bethesda, Md.: Naval Medical Research Institute.

SMITH, S., MYERS, T. I., \& JOHNSON, E., III. Stimulation seeking throughout seven days of sensory deprivation. Percept. mot. Skills, in press.

SMITH, S., MYERS, T. I., JOHNSON, E., III, MILSTEIN, S. L., WALSH, J. M., MARLOW, E. S., III, \& KUSHNER, E. N. Procedural details for project COMONOT. Res. Rep. No. 28, June, 1967. Bethesda, Md.: Naval Medical Research Institute.

SMITH, S., MYERS, T. I., \& MURPHY, D. B. Vigilance during sensory deprivation. Percept. mot. Skills, 1967, 24, 971-976.

ZUBEK, J. P., AFTANAS, M., HASEK, J., SANSOM, W., SCHLUDERMANN, E., WILGOSH, L., \& WINOCUR, G. Intellectual and perceptual changes during prolonged perceptual deprivation: low illumination and noise level. Percept. mot. Skills, 1962, 15, 171-198.

ZUBEK, J. P., PUSHKAR, D., SANSOM, W., \& GOWING, J. Perceptual changes after prolonged sensory isolation (darkness and silence). Canad. J. Psychol, 1961, 15, 83-100.

Note

1. From Bureau of Medicine and Surgery, Navy Dept., Research Task MF022. 01. 03-1002. The opinions and statements contained herein are the private ones of the writers and are not to be construed as official or as reflecting the views of the Navy Dept. or the Naval Servise at large. We note with particular gratitude the contributions of Eugene Johnson, III, Estelle N. Kushner, Peter M. Edmondo, Steven L. Milstein, Edwin S. Marlow, III, J. Michael Walsh, and Mary J. Holiman. 